\title{
The Interrelation between Transketolase and Dihydroxyacetone Synthase Activities in the Methylotrophic Yeast Candida boidinii
}

\author{
By M. J. WAITES AND J. R. QUAYLE* \\ Department of Microbiology, The University, Sheffield S10 2TN
}

(Received 8 December 1980)

\begin{abstract}
Crude extracts of Candida boidinii grown on glucose, xylose or ethanol gave single peaks of classical transketolase activity following chromatography on columns of hydroxylapatite; the enzyme was heat-stable and showed no appreciable activity with formaldehyde as acceptor in place of ribose 5-phosphate. Extracts of methanol-grown cells showed two peaks of transketolase activity following chromatography on both hydroxylapatite and DEAEcellulose. One peak was identified with that found for the cells grown on substrates other than methanol; the other peak showed dihydroxyacetone synthase activity in addition to transketolase activity. Both activities in the latter peak were very unstable and have been ascribed to one enzyme on the basis of identical rates of denaturation at all temperatures tested between 0 and $40^{\circ} \mathrm{C}$. It is suggested that this enzyme is a special transketolase synthesized only during methylotrophic growth of the yeast and, in contrast to classical transketolase, is capable of using equally well either formaldehyde or ribose 5-phosphate as glycolaldehyde acceptor. A method based on heat treatment has been suggested for the simultaneous assay of both transketolases present in crude extracts of a methylotrophically grown yeast.
\end{abstract}

\section{INTRODUCTION}

A key step in the pentose phosphate cycle of formaldehyde fixation which has been found to operate in growth of methylotrophic yeasts on methanol is the transfer of a glycolaldehyde fragment (most probably donated by xylulose 5-phosphate) to formaldehyde, with the formation of dihydroxyacetone (DHA) and glyceraldehyde 3-phosphate, catalysed by a special type of transketolase (Kato et al., 1979; Waites \& Quayle, 1980; O'Connor \& Quayle, 1980). Unlike the classical transketolase (EC 2.2.1.1) found in a variety of tissues, this special transketolase (DHA synthase) from Candida boidinii or Hansenula polymorpha appeared to be unstable and consequently difficult to purify (O'Connor \& Quayle, 1980). It has been shown that DHA synthase activity is only present in methanol-grown cells (Kato et al., 1979; Waites \& Quayle, 1980; O'Connor \& Quayle, 1980) and this activity has been separated from a peak of classical transketolase activity by ion-exchange chromatography of extracts of methanol-grown C. boidinii (O'Connor \& Quayle, 1980). By contrast, classical transketolase activity is present in extracts of $C$. boidinii and $H$. polymorpha at relatively high levels during growth on many substrates, including methanol (O'Connor \& Quayle, 1980). It has now been discovered that DHA synthase itself exhibits classical transketolase activity; the evidence for this finding and interrelationships between these different enzyme activities during growth of $C$. boidinii on several substrates are described in the present paper. Throughout the paper the term 'classical transketolase' will be used to describe an enzyme which catalyses glycolaldehyde transfer between xylulose 5-phosphate as donor and ribose 5-phosphate as acceptor. 


\section{METHODS}

Abbreviations. DHA, dihydroxyacetone; DHAP, dihydroxyacetone phosphate; GAP, glyceraldehyde 3phosphate; RiMP, ribose 5-phosphate; TPP, thiamin pyrophosphate; XuMP, xylulose 5-phosphate.

Organism and growth conditions. Candida boidinii CBS 5777 was grown in shake flasks at $30^{\circ} \mathrm{C}$ in the mineral salts medium of van Dijken et al. (1976). Filter-sterilized methanol $(0.5 \%$, w/v) or ethanol $(0.2 \%$, w/v) and autoclaved glucose or xylose $(0.2 \%, \mathrm{w} / \mathrm{v})$ were used as carbon and energy sources. For all studies, cultures were harvested in late-exponential phase by centrifugation at $6000 \mathrm{~g}$ for $20 \mathrm{~min}$.

Preparation of extracts. Cell-free extracts were prepared by ultrasonication (MSE model $150 \mathrm{~W}$ ) at $0{ }^{\circ} \mathrm{C}$ for 6 $\times 1$ min at 1 min intervals in 3 vol. $10 \mathrm{mM}-\mathrm{KH}_{2} \mathrm{PO}_{4} / \mathrm{NaOH}$ buffer $\mathrm{pH} 7.1$ containing $0.005 \%$ (w/v) TPP (for purification by hydroxylapatite chromatography) or $20 \mathrm{mM}$-glycylglycine buffer $\mathrm{pH} 7.6$ containing $5 \mathrm{mM}-\mathrm{MgCl}_{2}$ and $0.005 \%$ (w/v) TPP (for purification by DEAE-cellulose chromatography). Supernatants obtained following centrifugation at $38000 \mathrm{~g}$ for $20 \mathrm{~min}$ were used for all enzyme studies.

Enzyme assays. All assays were carried out in $1 \mathrm{ml}$ total volume at $30^{\circ} \mathrm{C}$ using a Pye Unicam SP 1800 double-beam recording spectrophotometer.

Transketolase (EC 2.2.1.1) was assayed by a modification of the method of de la Haba et al. (1955) using an equilibrium mixture of pentose phosphates generated by the addition of RiMP (initial concentration $5 \mathrm{~mm}$ ) in the presence of RiMP isomerase (EC 5.3.1.6; 1.5 units), ribulose-5-phosphate 3-epimerase (EC 5.1.3.1; 1.5 units) and excess of a commercial mixture of triosephosphate isomerase (EC 5.3.1.1) and glycerol-3-phosphate dehydrogenase (EC 1.1.1.8) (Boehringer).

DHA synthase activity was assayed using a test system containing: glycylglycine buffer $\mathrm{pH} 7 \cdot 6,50 \mathrm{~mm}$; $\mathrm{MgCl}_{2}, 2 \mathrm{mM}$; NADH, 0.15 mM; TPP, $0.005 \%(\mathrm{w} / \mathrm{v}) ;$ ATP, $1 \mathrm{mM}$; triosephosphate isomerase, 6 units; glycerol-3-phosphate dehydrogenase, 0.4 unit; glycerol kinase (EC 2.7.1.30; from Candida mycoderma), 2 units. A 'blank' system was also set up containing glycylglycine buffer, $\mathrm{MgCl}_{2}$ and $\mathrm{NADH}$ at the same concentrations. A sample of cell-free extract was added to both blank and test cuvettes, which were then incubated in the spectrophotometer for $3 \mathrm{~min}$. During this time no significant change in absorbance occurred as NADH oxidase activity was the same in each cuvette. XuMP then was added to the test cuvette to a final concentration of $2.5 \mathrm{mM}$, and an equal volume of distilled water was added to the blank. XuMP-dependent NADH oxidation (due to classical transketolase activity, resulting from the presence of pentose phosphate-interconverting activities and also the possible contamination of the commercial XuMP with RiMP) was monitored for 3 to 4 min to allow a steady rate to become established. Formaldehyde was then added to both cuvettes to a final concentration of $1 \mathrm{~mm}$. The observed increase in the rate of NADH oxidation was taken to be the result of formaldehyde- and XuMP-dependent formation of triose phosphates. Any contribution of formaldehyde reductase activity was compensated for by a similar rate occurring in the blank cuvette and being automatically subtracted from that occurring in the test cuvette. In crude extracts a discontinuous method, based on measurement of the XuMP-dependent rate of removal of formaldehyde (Waites \& Quayle, 1980), was also used where indicated.

The unit of activity was taken to be that amount of enzyme which catalysed the formation of $1 \mu \mathrm{mol}$ DHA $\mathrm{min}^{-1}$ under the conditions of assay. In the continuous spectrophotometric assay, calculation of the number of units entailed halving the rate of NADH oxidation observed since two triose phosphate equivalents were produced and estimated for each equivalent of DHA initially generated (see Results).

Partial purification of transketolase and DHA synthase. Method 1: Hydroxylapatite chromatography. Crude cell-free extracts (10 to $25 \mathrm{ml}$ ) containing 100 to $200 \mathrm{mg}$ protein were applied directly to a column $(10 \times 2 \mathrm{~cm})$ of hydroxylapatite (Biogel HTP, Bio-Rad Laboratories) equilibrated with the appropriate sonication buffer. The extract was washed on to the column with 20 to $30 \mathrm{ml}$ of the same sonication buffer and proteins were then eluted with a linear phosphate gradient ( 10 to $400 \mathrm{~mm}$, made up in $400 \mathrm{ml}$ of the same sonication buffer).

Method 2: DEAE-cellulose chromatography. Crude cell-free extracts (20 to $25 \mathrm{ml})$ were applied directly to a column $(5 \times 4 \mathrm{~cm})$ of DEAE-cellulose (Whatman DE 52) equilibrated with the appropriate sonication buffer. The extract was washed on to the column with 20 to $30 \mathrm{ml}$ of the same sonication buffer and proteins were then eluted with a linear $\mathrm{NaCl}$ gradient ( 0 to $0.3 \mathrm{M}$, made up in $400 \mathrm{ml}$ of the same sonication buffer).

Analytical methods and chemicals. Protein was estimated by the Lowry method using bovine serum albumin as standard. Biochemicals and enzymes were purchased from Boehringer, except transketolase, hydroxypyruvate, RiMP and XuMP which were obtained from Sigma. Formaldehyde was prepared from an aqueous suspension of paraformaldehyde by heating in a sealed ampoule at $110^{\circ} \mathrm{C}$ for 16 to $24 \mathrm{~h}$.

\section{RESULTS}

\section{Assay of dihydroxyacetone synthase}

O'Connor \& Quayle (1980) described a continuous spectrophotometric assay for DHA synthase (reaction 1) which consisted of coupling the formation of DHA to the action of glycerol kinase (reaction 2) and glycerol-3-phosphate dehydrogenase (reaction 3): 
Table 1. Specific activities of DHA synthase and classical transketolase in crude extracts of C. boidinii grown on various substrates

The assay method for DHA synthase was the discontinuous procedure (see Methods).

\begin{tabular}{lcc} 
Growth & \multicolumn{2}{c}{$\begin{array}{c}\text { Specific activity } \\
\text { substrate }\end{array}$} \\
\cline { 2 - 3 } DHA synthase & Transketolase \\
Methanol & 0.086 & 0.116 \\
Glucose & 0.007 & 0.098 \\
Xylose & 0.017 & 0.245 \\
Ethanol & ND & 0.060
\end{tabular}

ND, None detected.

Table 2. Specific activities of DHA synthase and classical transketolase in crude extracts of glucose-grown C. boidinii after transfer to methanol growth medium

Glucose-grown cells $(4.5 \mathrm{~g})$ of $C$. boidinii were harvested in mid-exponential phase, washed with sterile $20 \mathrm{mM}-\mathrm{KH}_{2} \mathrm{PO}_{4} / \mathrm{NaOH}$ buffer $\mathrm{pH} 7 \cdot 1$, and resuspended in 31 methanol growth medium. Cultures were then incubated at $30^{\circ} \mathrm{C}$ in shake flasks. The assay method for DHA synthase was the discontinuous procedure (see Methods).

$$
\begin{array}{ccc}
\begin{array}{c}
\text { Time after } \\
\text { resuspension }(\mathrm{h})
\end{array} & \overbrace{\text { DHA synthase }}^{\left[\mu \mathrm{mol} \mathrm{min}^{-1}{\text { (mg protein } \left.)^{-1}\right]}^{\text {Specif activity }}\right.} \\
0 & 0.006 & 0.080 \\
16 & 0.048 & 0.067 \\
24 & 0.074 & 0.071 \\
\mathrm{HCHO}+\mathrm{XuMP} \rightarrow \text { DHA + GAP } & \\
\text { DHA + ATP } \rightarrow \text { DHAP + ADP } & \\
\text { DHAP + NADH + H } & \rightarrow \text { L-Glycerol 3-phosphate + NAD }{ }^{+}
\end{array}
$$

In order to correct for the presence of many interfering activities in crude extracts, each assay had to be performed twice with a different order of addition of reactants. The improved method described in the Methods section of the present paper obviates the need for duplicate assay with consequent saving of expensive reagents and time. Furthermore, by including triosephosphate isomerase in the assay mixture, the GAP produced in reaction (1) is isomerized to DHAP and is also detected by reaction (3), thus resulting in a twofold amplification of the rate of reaction (1) under conditions in which endogenous triosephosphate isomerase, originally present in the enzyme extract, may have been progressively removed during enzyme purification.

\section{Synthesis of two transketolases during methylotrophic growth of C. boidinii}

The specific activities of DHA synthase and classical transketolase were determined in crude extracts of $C$. boidinii grown on various substrates (Table 1). Appreciable DHA synthase activity was only detected in methanol-grown cells, whereas classical transketolase activity was found during growth on all substrates tested. Glucose-grown cells, containing an insignificant level of DHA synthase activity, when transferred to methanol growth medium showed increasing DHA synthase activity during the lag period of no growth, but classical transketolase activity remained relatively constant (Table 2). This indicated that the two activities were due to two different enzymes. 


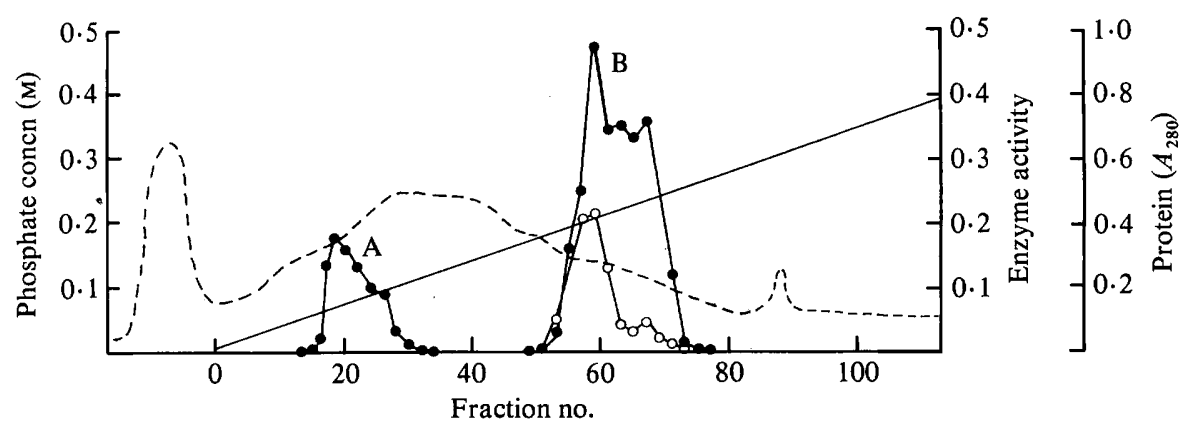

Fig. 1. Separation of two classical transketolase activities, one of which has DHA synthase activity, by chromatography of a crude extract of methanol-grown $C$. boidinii on hydroxylapatite. The extract (containing $100 \mathrm{mg}$ protein) was passed through a column of hydroxylapatite using a linear phosphate gradient; details are given in Methods. Samples $(50 \mu \mathrm{l})$ of fractions $(3.5 \mathrm{ml})$ were assayed for enzyme

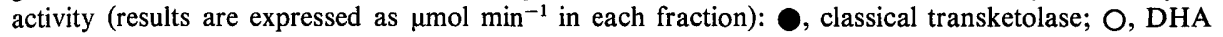
synthase; -

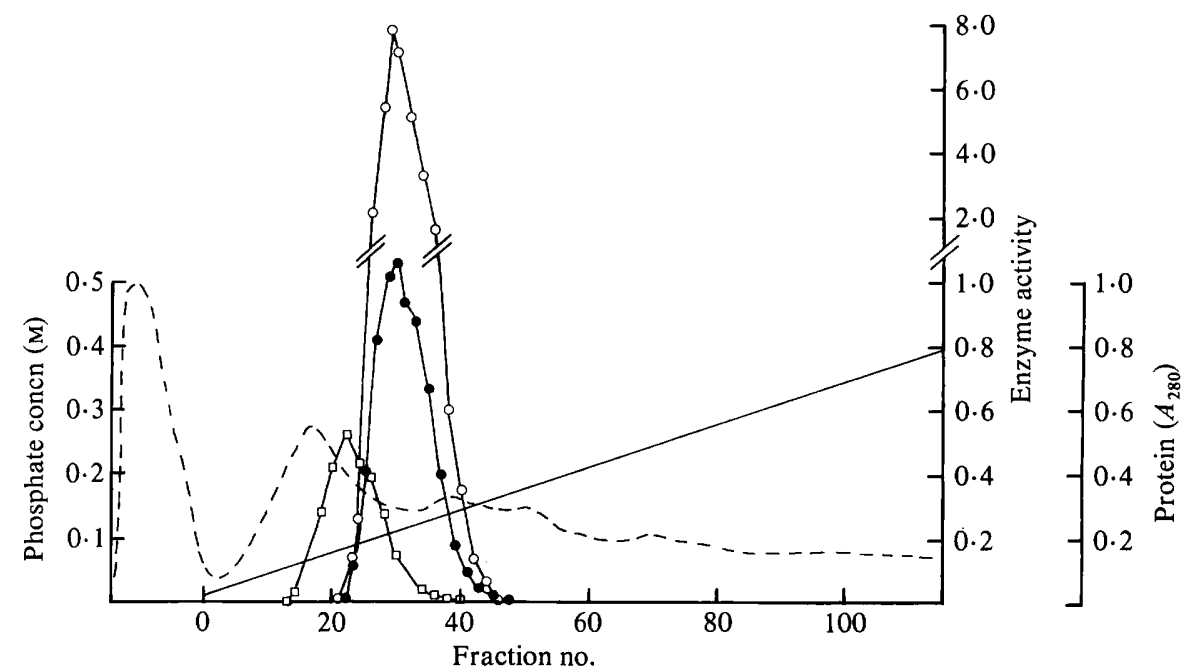

Fig. 2. Partial purification of classical transketolase from crude extracts of $C$. boidinii grown on various substrates. Extracts (containing $100 \mathrm{mg}$ protein) were passed through separate columns of hydroxylapatite with identical linear phosphate gradients; details are given in Methods. Samples (20 to $50 \mu \mathrm{l})$ of fractions $(3.5 \mathrm{ml})$ were assayed for transketolase activity (results are expressed as $\mu \mathrm{mol} \mathrm{min}^{-1}$ in each fraction): $\bigcirc$, xylose-grown cells; $O$, glucose-grown cells; $\square$, ethanol-grown cells; phosphate gradient; ----, absorbance at $280 \mathrm{~nm}$ obtained with the extract from glucose-grown cells.

In previous studies (O'Connor \& Quayle, 1980), DHA synthase activity was found to be very unstable, resulting in low yields during purification. In the present study, attempts to stabilize DHA synthase activity by the addition of compounds such as formaldehyde, EDTA, $\left(\mathrm{NH}_{4}\right)_{2} \mathrm{SO}_{4}$, methanol, ethanol, dithiothreitol, XuMP, and the protease inhibitor phenylmethylsulphonyl fluoride were unsuccessful. However, addition of $0.005 \%(w / v)$ TPP to all buffers used in the handling of the yeast extracts was found to have a slightly beneficial effect.

As large losses occurred at each stage of a purification, attempts were made to purify DHA synthase by direct chromatography of cell-free extracts on hydroxylapatite. Extracts of methanol-grown cells gave two peaks (A and B) of classical transketolase activity (Fig. 1), one of which (peak B) also contained DHA synthase activity. Extracts from cells grown on other substrates merely gave single peaks of classical transketolase activity, which were eluted from the columns at approximately the same position as the peak A from methanol-grown cells (Fig. 2). Thus, the peak containing both DHA synthase and classical transketolase 


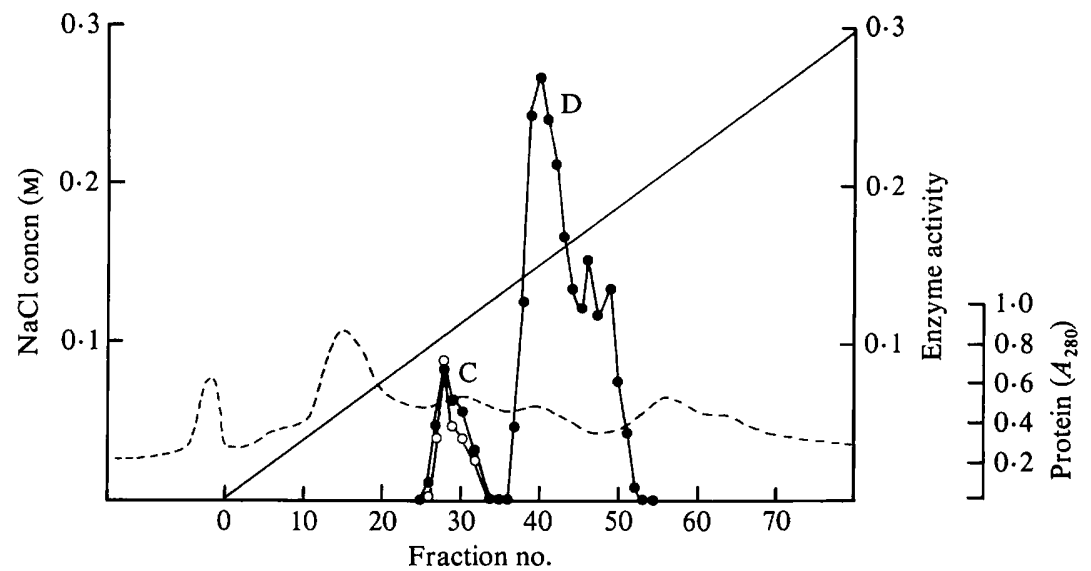

Fig. 3. Separation of two classical transketolase activities, one of which has DHA synthase activity, by chromatography of a crude extract of methanol-grown $C$. boidinii on DEAE-cellulose. The extract (containing $100 \mathrm{mg}$ protein) was passed through a column of DEAE-cellulose $\left(\mathrm{Cl}^{-}\right.$form) using a linear $\mathrm{NaCl}$ gradient; details are given in Methods. Samples $(50 \mu \mathrm{l})$ of fractions $(5 \mathrm{ml})$ were assayed for

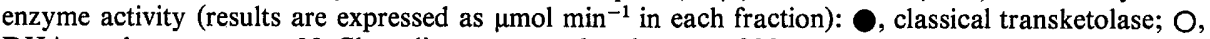
DHA synthase; -, $\mathrm{NaCl}$ gradient; ----, absorbance at $280 \mathrm{~nm}$.

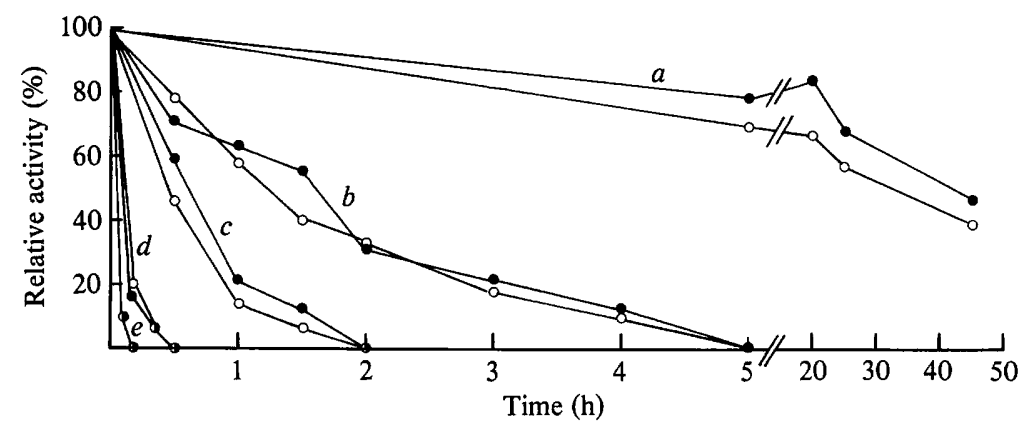

Fig. 4. Thermal stability of the enzyme(s) contained in the combined fractions of peak B (see Fig. 1): $\mathrm{O}$, classical transketolase; $\mathrm{DHA}$ synthase. Incubation temperature: $a, 0^{\circ} \mathrm{C} ; b, 20^{\circ} \mathrm{C} ; c, 30^{\circ} \mathrm{C} ; d$, $35^{\circ} \mathrm{C} ; e, 40^{\circ} \mathrm{C}$.

activities was only found in extracts of methanol-grown cells, whereas the peak containing classical transketolase activity alone was present in extracts of cells grown on all substrates tested, including methanol.

Attempts were made to separate the two activities of peak $B$ by ion-exchange chromatography. Pooled fractions were dialysed and submitted to DEAE-cellulose chromatography. Major portions of both activities were lost during dialysis and neither activity was detected in eluate fractions from the ion-exchange column. A crude cell-free extract of methanol-grown cells was then applied directly to a DEAE-cellulose column and eluted with a linear $\mathrm{NaCl}$ gradient (Fig. 3). Two peaks of classical transketolase activity were detected; the first, and smaller, peak (C) also had DHA synthase activity in contrast to the larger peak (D) which did not. Extracts from glucose-grown cells produced only one peak of classical transketolase activity, which eluted in the same position as did peak D of extracts from methanol-grown cells.

In order to establish whether the two activities occurring together in peak B (Fig. 1) were due to the same enzyme, samples from the combined fractions of peak B were incubated at various temperatures $\left(0\right.$ to $\left.40^{\circ} \mathrm{C}\right)$ and the two activities were monitored (Fig. 4). Classical transketolase and DHA synthase activities disappeared at the same rates at the five 


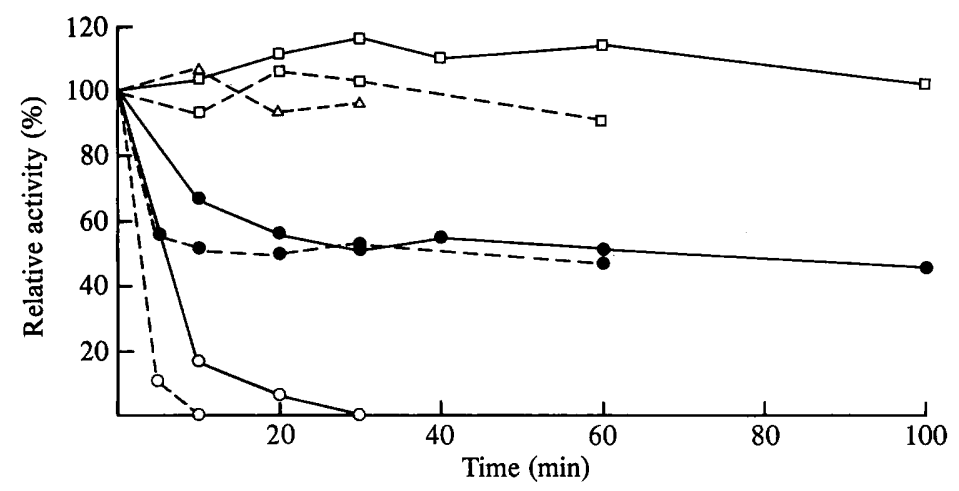

Fig. 5. Thermal stability of classical transketolase (O), DHA synthase (O) and NADH oxidase ( $\square$ ) activities in crude extracts of methanol-grown $C$. boidinii, and classical transketolase $(\triangle)$ from glucose-grown C. boidinii, monitored during incubation at $35^{\circ} \mathrm{C} \mathrm{(}-$ and $40^{\circ} \mathrm{C}(----)$.

temperatures used. Activities were found to be relatively stable when maintained at $0{ }^{\circ} \mathrm{C}$, but were totally lost within 10 or $30 \mathrm{~min}$ at 40 and $35^{\circ} \mathrm{C}$, respectively. Crude extracts of methanol-grown cells subjected to the same heat treatment lost approximately $50 \%$ of classical transketolase activity within 10 or $30 \mathrm{~min}$ at 40 and $35^{\circ} \mathrm{C}$, respectively, with accompanying total loss of DHA synthase activity (Fig. 5). The remaining classical transketolase activity was very stable, losing little further activity over the next hour. Over the whole period, NADH oxidase activity remained relatively constant, thus showing that non-specific protease activity was not responsible for the loss of enzyme activities.

In peaks $B$ and $C$ the ratios of DHA synthase activity to classical transketolase activity were approximately $1: 2$ and $1: 1$, respectively (see Figs 1 and 3). Classical transketolase activity was routinely assayed by addition of RiMP to an initial concentration of $5 \mathrm{~mm}$ in a system containing pentose phosphate-interconverting enzymes, resulting in an equilibrium mixture of RiMP : ribulose 5-phosphate:XuMP (75:25:75) (Tabachnick et al., 1958) and thus an equilibrium concentration of approximately $2.1 \mathrm{mM}$ for both RiMP and XuMP. The substrate concentrations of XuMP and formaldehyde used for the routine assay of DHA synthase were $2.5 \mathrm{~mm}$ and $1 \mathrm{mM}$, respectively. In order to compare the reactivities of the two alternative glycolaldehyde acceptors, namely RiMP and formaldehyde, DHA synthase and classical transketolase activities of the combined fractions of peak B were determined using assay concentrations of $2.5 \mathrm{mM}$ for the glycolaldehyde donor (XuMP) and $1.0 \mathrm{mM}$ for the acceptor (formaldehyde or RiMP). Under these conditions the ratio of activity with the two acceptors was approximately $1: 1$.

Hydroxypyruvate was also tested as an alternative glycolaldehyde donor, in place of XuMP, with formaldehyde as the acceptor. Rates with partially purified DHA synthase were approximately $35 \%$ of those obtained using equimolar XuMP. Tani et al. (1980) have reported similar results with the partially purified DHA synthase from Kloeckera sp. 2201.

The classical transketolase peaks (A and D) observed in extracts from methanol-grown cells (Figs 1 and 3 ) and the single peaks found during growth on other substrates (Fig. 2) did not exhibit appreciable DHA synthase activity, but low rates might be expected since Dickens \& Williamson (1958) showed that in the presence of purified classical transketolase from baker's yeast, formaldehyde slowly accepts a glycolaldehyde fragment donated by hydroxypyruvate. In these experiments $500 \mu \mathrm{g}$ transketolase in $2.5 \mathrm{ml}$ reaction mixture catalysed a rate of reaction between these substrates of 15 to $18 \mu \mathrm{mol}$ over $2 \mathrm{~h}$ incubation at $37^{\circ} \mathrm{C}$. Without a progress curve for the reaction it is not possible to establish the specific activity of the enzyme from these data. We therefore tested the highly purified classical transketolase from baker's yeast (Sigma) for DHA synthase activity using our own 
continuous spectrophotometric assay with $2.5 \mathrm{mM}$-XuMP and $1 \mathrm{mM}$-formaldehyde as substrates. A rate of $0.245 \mu \mathrm{mol} \mathrm{min}^{-1}$ (mg protein) ${ }^{-1}$ was observed which was $1 \%$ of the rate found when RiMP replaced formaldehyde as acceptor. If the classical transketolase from C. boidinii behaves similarly to that from baker's yeast, and there is no reason to suppose otherwise, it can be calculated that the activity of the former enzyme with formaldehyde as acceptor could not have been detected by the continuous spectrophotometric assay in samples of the appropriate peaks taken from the columns described in Figs 1, 2 and 3 without considerable further purification and concentration of the enzyme contained therein.

\section{DISCUSSION}

These results show that $C$. boidinii can synthesize two transketolases: (a) an unstable enzyme exhibiting both DHA synthase and classical transketolase activities; (b) a relatively stable enzyme exhibiting only classical transketolase activity. The former enzyme is only synthesized during growth on methanol, whereas the latter enzyme is synthesized during growth on all substrates tested, including methanol. It is thus clear that measurements of classical transketolase activity (using XuMP as donor and RiMP as acceptor) in crude extracts of a methylotrophic yeast can give a composite figure for two enzymes depending on the growth conditions. A convenient method for separating this composite figure into its two components (in $C$. boidinii at least) would be first to measure the DHA synthase activity with $\mathrm{XuMP}$ and formaldehyde, and then to heat the extracts for $10 \mathrm{~min}$ at $40^{\circ} \mathrm{C}$ or $30 \mathrm{~min}$ at $35^{\circ} \mathrm{C}$ before measuring the classical transketolase activity with XuMP and RiMP.

It is not clear at this stage why in the previous study of O'Connor \& Quayle (1980) classical transketolase activity was not detected in the peak of DHA synthase activity obtained by DEAE-cellulose chromatography. Due to heavy losses of enzyme activity during the desalting on Sephadex G-25 and chromatography on DEAE-cellulose, the levels of DHA synthase that were finally assayed by these authors were very low and hence assays were not as accurate as in the one-step separation procedure developed in the present study. The greater accuracy of assay that is attainable with greater enzyme activities may indeed be one factor involved; however, this may not be the primary factor. During the present study it was observed that in peaks exhibiting dual activity of DHA synthase and classical transketolase, the ratio of the former activity to the latter varied from approximately $1: 2$ to $1: 1$ depending upon the method of purification (compare peak B in Fig. 1 with peak C in Fig. 3). This suggests that certain treatments of the enzyme, e.g. ion-exchange chromatography, can alter its relative reactivity towards formaldehyde and RiMP as glycolaldehyde acceptors. It should also be noted that passage of a crude extract through a DEAE-cellulose column caused much greater losses of DHA synthase activity than did a similar passage through a hydroxylapatite column. Further work is needed to explore this.

It has long been known that the classical transketolase of baker's yeast can slowly utilize hydroxypyruvate as glycolaldehyde donor and formaldehyde as acceptor (Dickens \& Williamson, 1958). We have further shown that, as might be expected, this enzyme also exhibits a low DHA synthase activity of approximately $1 \%$ of its classical transketolase activity. Similarly, it has been found that hydroxypyruvate can replace XuMP as a glycolaldehyde donor for the DHA synthase found in methanol-grown C. boidinii.

An interesting problem is raised by the high classical transketolase activity displayed by DHA synthase. Does the former activity play any physiological role during growth on methanol? Classical transketolase is expected to play a key role in the XuMP cycle of formaldehyde fixation during the regeneration of pentose phosphate from fructose phosphate and triose phosphate (van Dijken et al., 1978). Can DHA synthase assume this role as well as that of formaldehyde fixation, or is it left to the second classical transketolase which is present under all growth conditions? Mutant studies may help to answer this question.

We thank Mr N. D. Lindley for helpful discussion and assistance and the Science Research Council for support under grant no. GR/A/65966. 


\section{REFERENCES}

Dickens, F. \& Williamson, D. H. (1958). Formaldehyde as an acceptor aldehyde for transketolase, and the biosynthesis of triose. Nature, London 181, 1790.

DE LA HABA, G., Leder, I. G. \& RACKer, E. (1955). Crystalline transketolase from baker's yeast: isolation and properties. Journal of Biological Chemistry 214, 409-426.

Kato, N., Nishizawa, T., Sakazawa, C., Tani, Y. \& YAMADA, H. (1979). Xylulose 5-phosphate dependent fixation of formaldehyde in a methanol-utilizing yeast Kloeckera sp. no. 2201. Agricultural and Biological Chemistry 43, 2013-2015.

O'ConNoR, M. L. \& QUAYLE, J. R. (1980). Pentose phosphate-dependent fixation of formaldehyde by methanol-grown Hansenula polymorpha and Candida boidinii. Journal of General Microbiology 120, 219-225.

Tabachnick, M., SRere, P. A., CoOPer, J. \& RACKER, E. (1958). Oxidative pentose phosphate cycle III. The interconversion of ribose 5-phosphate, ribulose 5-phosphate and xylulose 5-phosphate. Archives of Biochemistry and Biophysics 74, 315325.
Tani, Y., Nishizawa, T., Yamada, H., Kato, N. \& SAKAZAWA, C. (1980). The first enzyme for the assimilation pathway of methanol in Kloeckera sp. no. 2201. 3rd International Symposium on Microbial Growth on $C_{1}$-Compounds, Sheffield, U.K. (Abstract).

van Disken, J. P., OTto, R. \& HARDER, W. (1976). Growth of Hansenula polymorpha in a methanollimited chemostat. Physiological responses due to involvement of methanol oxidase as a key enzyme in methanol metabolism. Archives of Microbiology 111, 137-144.

van DiJken, J. P., HARder, W., Beardsmore, A. J. \& QUAYLE, J. R. (1978). Dihydroxyacetone: an intermediate in the assimilation of methanol by yeasts? FEMS Microbiology Letters 4, 97-102.

W AITES, M. J. \& QUAYLE, J. R. (1980). Dihydroxyacetone: a product of xylulose 5-phosphatedependent fixation of formaldehyde by methanolgrown Candida boidinii. Journal of General Microbiology 118, 321-327. 